\title{
EVALUATION OF CANOLA BIODIESEL PURIFICATION FOR ITS USING AS A SUBSTITUTE FOR DIESEL FUEL IN RURAL COMMUNITIES
}

\author{
El-Wehishy ${ }^{1}$, M.M.; M.M. Mostafa ${ }^{2}$; A.I. Moussa ${ }^{1}$ and M.A. El-Nono ${ }^{2}$ \\ [47] \\ 1- Power and Energy Researches Dept., Agric. Engineering Research Institute, Agric. Research \\ Center, Dokki, Giza, Egypt \\ 2- Agricultural Engineering Dept., Fac. of Agric., Ain Shams Univ., Cairo, Egypt
}

Keywords: Canola Biodiesel; Producing Biodiesel from Canola; Biodiesel Purification; Purification Using Organic Materials

\section{ABSTRACT}

The aim of this study was biodiesel purification with different methods beyond water by using different materials was used for this purpose. A large amount of biodiesel was produced from canola oil as source of oil therefore methanol alcohol had been added with potassium hydroxide $(\mathrm{KOH})$ as catalyst. After 8 hours, biodiesel was separated from glycerol where glycerol was under the biodiesel using gravity. To purify biodiesel from remains of glycerol, water and alcohol, some materials filled two filters. Materials were rice husk grind, bagasse grind, saw dust, magnesium silicate and water. The results showed that the water, methanol and glycerol contents were $0.04,0.01$ and $0.23 \%$ respectively with using grind bagasse, but they were $0.2,0.03$ and $0.24 \%$ respectively with using water in purification process. So the bagasse grind was better than other materials in purification process of canola biodiesel.

\section{INTRODUCTION}

Because of problems of petroleum fuel such as resources drop, prices increase and global warm grows, using another source of fuel is suitable for this time (O'Brien, 2004). Biodiesel can be used as alternative for diesel engines to solve this problem. Biodiesel is the commercial term of monoalkyl esters, which can be made from mixed alcohol with catalyst with triglyceride such as vegetable oils and animal fats that has the ASTM standards specifications. In diesel engines, biodiesel is burning like as petroleum diesel no difference between them. Also it has advantages more than the other like lubricating, emission less, organic resource, non-toxicity and regenerated (Joshi, 2008). Biodiesel is less toxic than salt and biodegrades as fast as sugar. Regular diesel fuel particulates are carcinogenic. Using canola biodiesel as fuel, or mixing it with diesel fuel, can decrease carcinogenic emissions. Biodiesel can be mixed with petroleum diesel in any ratio; the common ratio is $20 \%$ biodiesel $80 \%$ petroleum diesel which is named B20. To improve the efficiency of engine, it can used B20 as fuel for it which increase the Cetane No by 3 points.

Biodiesel is an organic-based fuel that generally consists of monoalkyl esters such as fatty acid methyl esters (FAME) or fatty acid ethyl esters (FAEE) which made from the transesterification process of triglycerides with methanol or ethanol, respectively. Canola can be used as source of biodiesel production. In transesterification process, using simple alcohols with the involvement of catalyst, such as potassium hydroxide or sodium hydroxide, that breaks the oil (triglyceride) into monoalkyl esters of oil and glycerol as a secondary product (Schuchardt et al 1998). The problem was the rise of water, alcohol and glycerol in the produced biodiesel that is purified with water which negatively affected on diesel engine. The principal aim of this research was to evaluate different materials used in purifying the biodiesel that may aid to find more effective ways to perform this action. Hence, the following objectives were addressed: (A) Manufacturing biodiesel using canola oil as source; (B) Purifying biodiesel using different materials beyond water; and $(C)$ Measuring the remains of water, methanol and glycerol contents in produced biodiesel. 


\section{MATERIALS AND METHODS}

\subsection{The source of the biodiesel}

The main source of the produced biodiesel is obtained from canola's oil was brought from The Standard Farm in El-Kilo 69, Alexandria-Cairo Desert Road, Production Sector, Agricultural Research Center, Ministry of Agriculture, Egypt. Also, triolein, hexane, anhydrous methanol (99.9\%) and $\mathrm{KOH}$ were purchased from Elictrosaint Chemical Co. in Kafr El-Sheikh.

\subsection{Determining of fatty acid composition}

The reference (ASTM) standards required for the Gas Chromatography (GC) analysis were in High Institute of public Health Alexandria University. The standards were solution of glycerol, 1- mono-olein, 1,3-di-olein (1\% 1,2 isomer) and triolein. n-Hexane (HPLC grade) was used as a solvent to dilute the samples for GC analysis. GC has been used to determine the fatty acid composition percentage of canola oil and its physicochemical properties determined as per BIS method (Arun K.V. et al 2013). Canola oil contains some different types of fatty acids. Different fractions of each type of fatty acids influence on the fuel properties.

\subsection{Pilot Biodiesel Plant}

Biodiesel was obtained from a pilot Biodiesel plant which is available at the Tractor Test Station in Sabahia, Alexandria, Egypt. Fig. (1) showed the pilot biodiesel plant. The pilot plant consists of two processors with heater for each one, three pumps, a chemical mixing tank and a purification unit for dry washing.

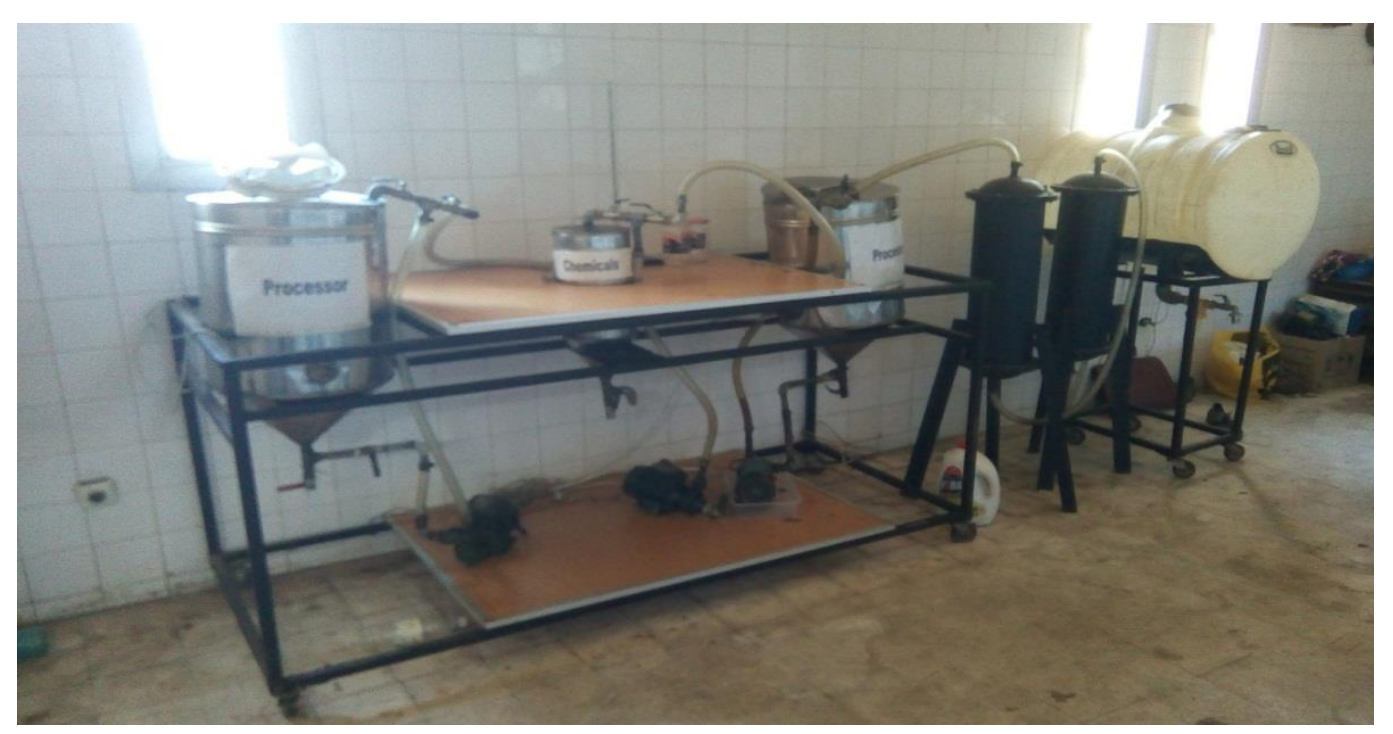

Fig.1. Pilot biodiesel plant in Alexandria

\subsection{Transesterification Process}

Two major inappropriate properties that influence the production process are water content and free fatty acid (FFA) percentage in the oil. Using vegetable oil directly is not suitable for engines; however, it is possible by reducing the viscosity of vegetable oil that lead to improve the physical properties through transesterification process.

The transesterification is the reaction and transformation by mixing the reactants. The percent of catalyst motivate the reaction to the product side. In order to achieve high yield of esters the alcohol has to be used in excess. In coexist of an alcohol and a catalyst, the reaction converts triglyceride to fatty acid alkyl ester, and glycerol is secondary product.

More alcohol is used because of the reaction is reversible to push reaction to product side. The molar masses of the esters are approximately one sixth that of the triglycerides which in turn leads to significant reduction in the viscosity. Thus it is therefore a good process to make petro diesel substitutes from vegetable oils. 


\subsubsection{Calculation of molar ratio}

- It has to know the molecular weight of canola oil and applying molar ratio $6: 1$; the number of oil moles could be estimated as follows:

Mass of oil, $\mathrm{gm}=$ Batch volume, $\mathrm{ml} \times$ oil density, $\mathrm{g} / \mathrm{ml}$

Number of oil moles $=$ Mass of oil, gm / oil molecular weight, $\mathrm{g} / \mathrm{mole}$

The resulted number of oil moles represents the parts of oil (one) in the applied molar ratio 6:1.

- Number of methanol moles = number of oil moles $\times$ parts of methanol ( 6 in the applied molar ratio).

Mass of methanol $=$ number of methanol moles $\times$ methanol molecular weight $32 \mathrm{~g} / \mathrm{mole}$.

Amount of methanol = mass of methanol $/$ methanol density $(0.79 \mathrm{~g} / \mathrm{ml})$

-The required amount of catalyst $\mathrm{KOH}$ is $1 \%$ by weight of the above specified batch of oil.

\subsubsection{Procedures of transesterification}

Berman et al (2011) and Conceicao et al (2007) reported that oil was heated up to $80{ }^{\circ} \mathrm{C}$ to evaporate water then was let to cool down to 50 ${ }^{\circ} \mathrm{C}$. Caylr and Kusefoglu (2008) reported that oil was heated up to $80{ }^{\circ} \mathrm{C}$ to evaporate water and then was left to cool down to $55^{\circ} \mathrm{C}$. The biodiesel was produced from 150 liters of canola's oil where 5 batches have been made. The procedures of the trans-esterification include the following steps:

The oil was pre-heated to $55^{\circ} \mathrm{C}$ so as the needed temperature for the trans-esterification process.

Titration process. No need to titrate canola oil as long as it is new. The amount of $\mathrm{KOH}$ needed per liter for fresh oil is $4.9 \mathrm{gm}$ of $\mathrm{KOH}$ / liter of oil.

In the premix tank, the potassium hydroxide (147 $\mathrm{g}$ ) is added to methanol (6 liter) and then stirred well by the closed circulation pump for about 20 min. potassium methoxide is formed as shown in the following equation:

$$
\mathrm{KOH}+\mathrm{CH}_{3} \mathrm{OH} \rightarrow \mathrm{KCH}_{3} \mathrm{O}+\mathrm{H}_{2} \mathrm{O}
$$

Potassium methoxide were pumped to the heated canola oil (30 liter) in the processor tank then they were stirring during circulation for $2 \mathrm{~h}$. During this time, trans-esterification process takes place. The reaction equation can be given as follow:

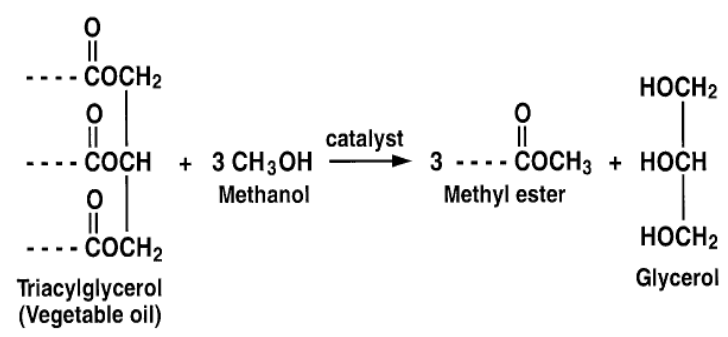

The theory of this operation is that the fatty acids of the oil exchange places with the $\mathrm{OH}$ group of the alcohol producing glycerol and the methyl ester (Moussa, 2003). The process is three steps reaction as shown below in Fig. (2).

$$
\begin{aligned}
& \text { Triglyceride }+ \text { Alcohol } \longleftrightarrow \text { Diglyceride }+ \text { Alkyl Esters } \\
& \text { Diglyceride }+ \text { Alcohol } \longleftrightarrow \text { Monoglyceride }+ \text { Alkyl Esters } \\
& \text { Monoglyceride }+ \text { Alcohol } \longleftrightarrow \text { Glycerol }+ \text { Alkyl Esters }
\end{aligned}
$$

Fig.2. Stepwise reaction of transesterification

The circulation is terminated and the mixture is allowed to make phase separation after eight hours. The glycerol is then decanted from the bottom while methyl ester is separated from ester phase.

\subsection{Purification of biodiesel}

To obtain biodiesel fuel with good quality, it is very important to choose the best method to get rid of chemicals, glycerin, and unreacted oil in the fuel. Biodiesel is traditionally purified by water washing process (Saengprachum et al 2013), followed by drying process. 


\subsubsection{Water washing}

In the washing tank water and biodiesel were stirred by using centrifuge pump for 9 min (Elshazly, 2015). Steps of water washing process:

-10 liters of water was added to 30 liters of biodiesel.

-Water was pumped to the biodiesel in the washing tank then they were stirring during circulation for 9 minutes.

-After finishing the stirring of the biodiesel left it to separate from the water, due to density difference between them. While water has higher density, so it will be settled down at lower position. After $1 \mathrm{hr}$. the water was taken out from biodiesel. $\mathrm{pH}$ meter was used to measure the $\mathrm{pH}$ of the water solution which is an indicator of the amount of the chemicals that removed.
The last step was repeated in three to four stages of washing until the $\mathrm{pH}$ number became in range of 7 to 7.5 . It is important to dry biodiesel to get rid of excess water.

\subsubsection{Dry washing}

Two filters were made for dry washing (fig. 3) .The first filter linked by a hose to the production processor and the other filter linked to an external tank by a hose too. The filters were filed with the adsorbent materials, and Fig.3. Dry washing filters then the produced biodiesel was pumped to the filters as two stages of washing then poured to the tank. Four materials were used in this process to study the effect of these materials on the purity of the biodiesel. These four adsorbent materials were grind bagasse, saw dust, grind rice husk and magnesium silicate as shown in Figures 4, 5, 6 and 7.

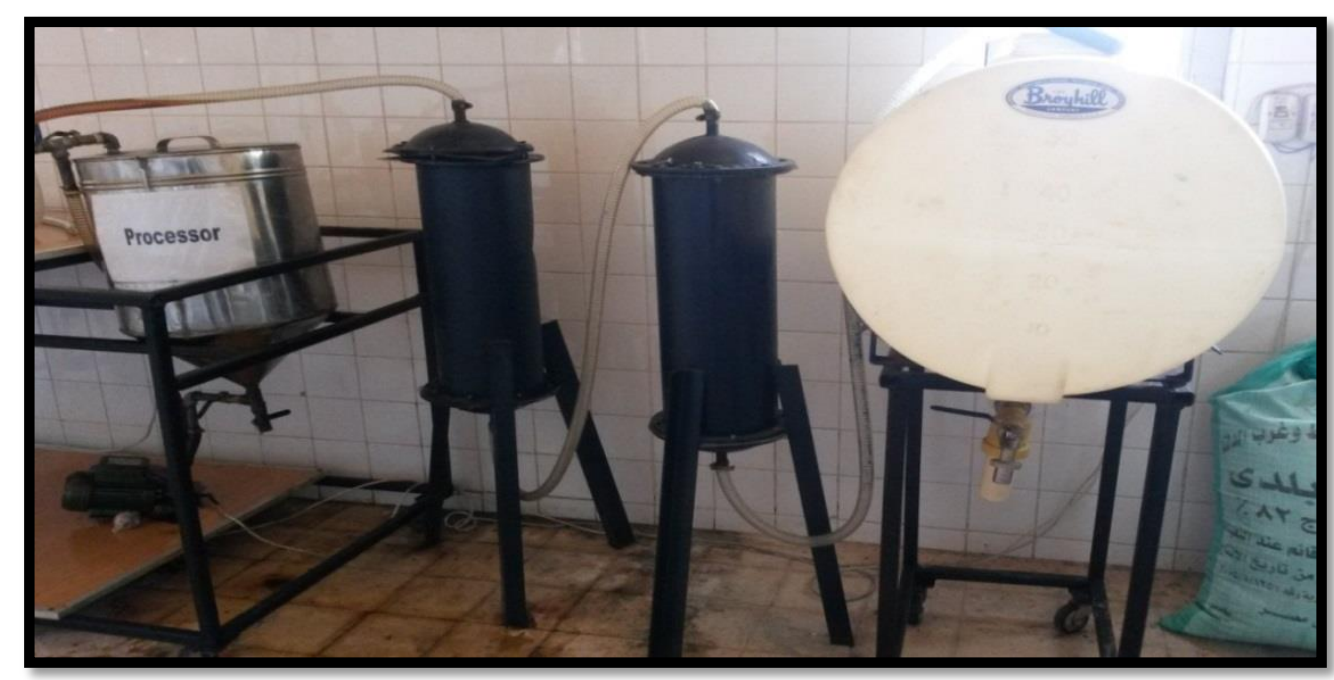

Fig. 3. Dry washing filters

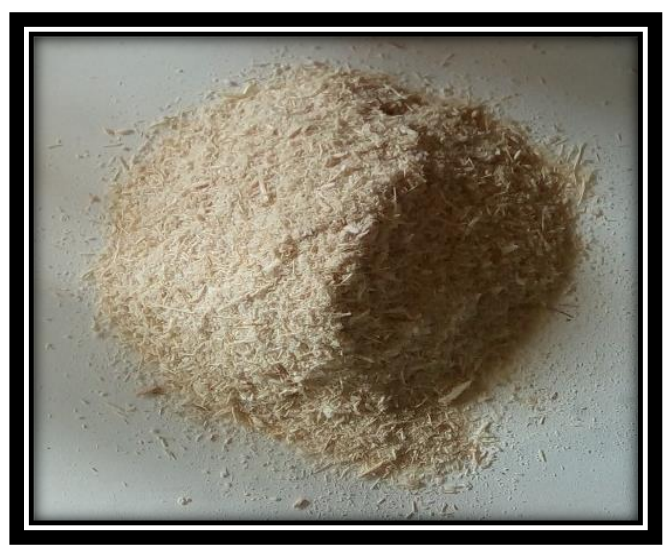

Fig. 4. The grind bagasse

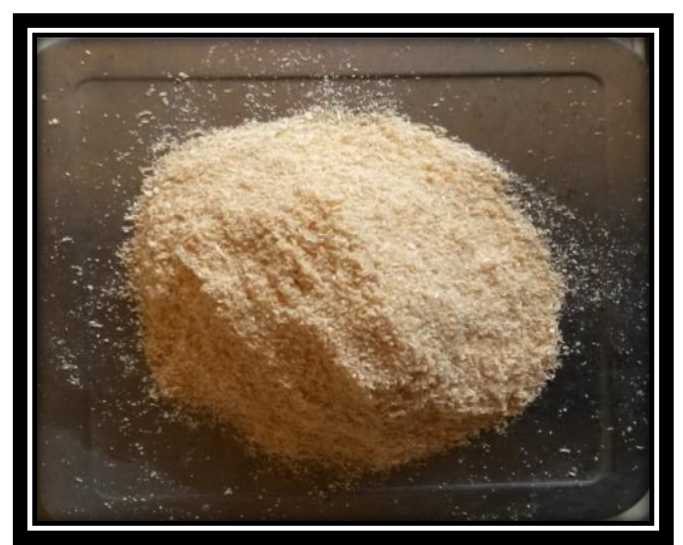

Fig. 5. The saw dust 


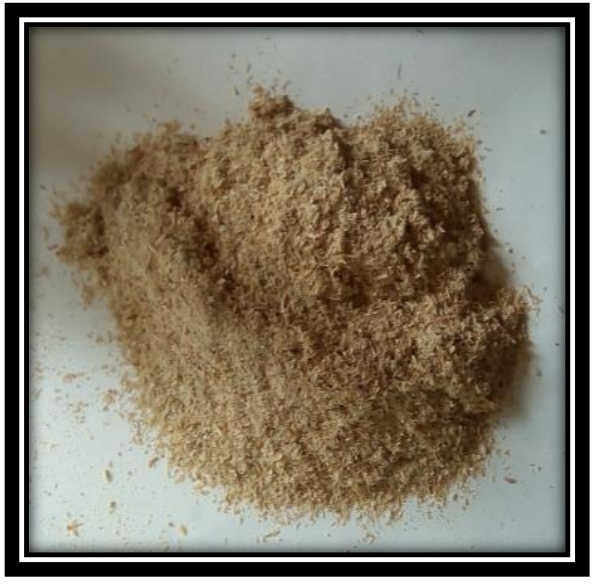

Fig. 6. The grind rice husk

\section{RESULTS AND DISCUSSION}

\subsection{Purification of biodiesel}

\subsubsection{Water washing}

After finishing the stirring of the biodiesel left it to separate from the water, $\mathrm{pH}$ was measured for the water solution which is an indicator of the amount of the chemicals that removed. When the

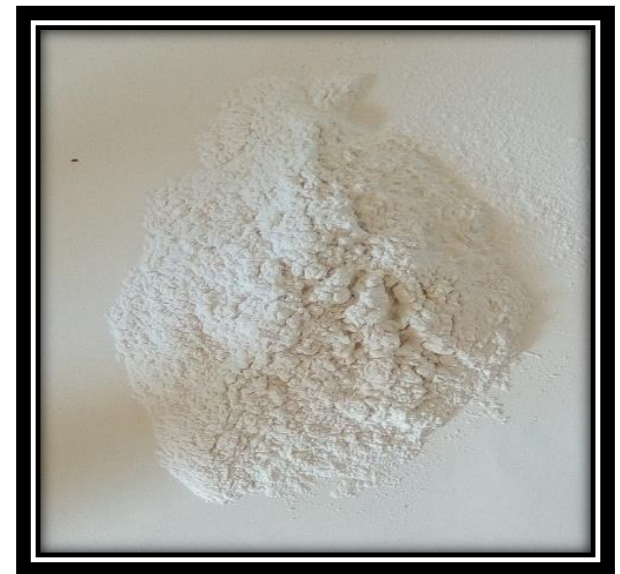

Fig.7. The magnesium silicate

$\mathrm{pH}$ number became in range of 7 to 7.5 . It is important to dry biodiesel to get rid of excess water. Fig. 8 shows that the water color become milky in the first washing and it became clear in the next washings gradually.

Fig. (9) shows the difference between biodiesel before and after washing, it is obvious that biodiesel after washing and drying become clearer than biodiesel before washing.

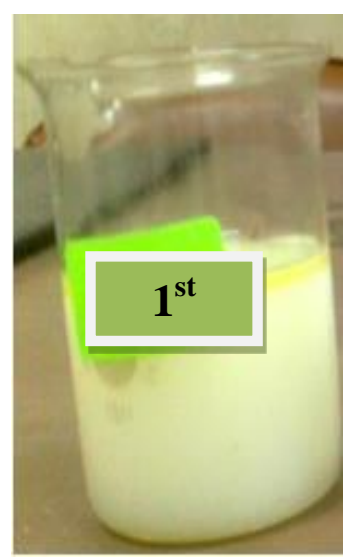

Milky

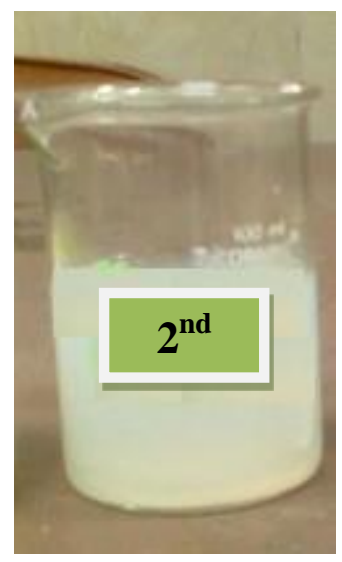

Marky

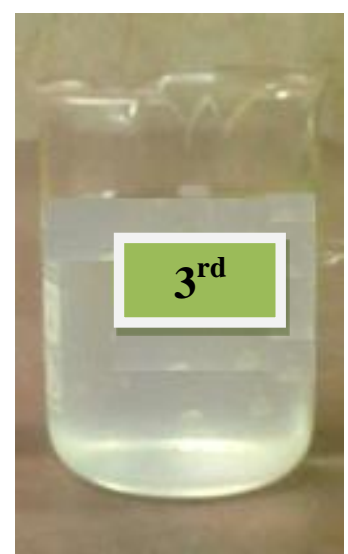

Clear

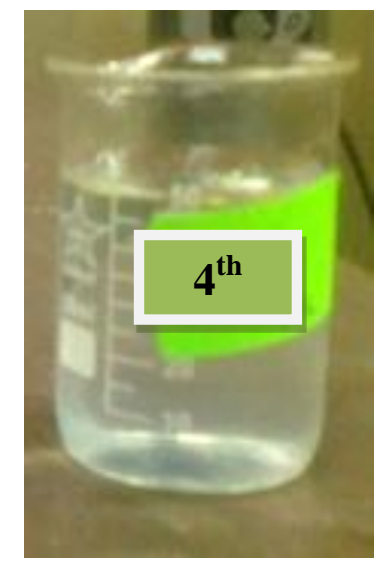

Very Clear

Fig. 8. Samples for the water of washing through the 4 stages of washing 


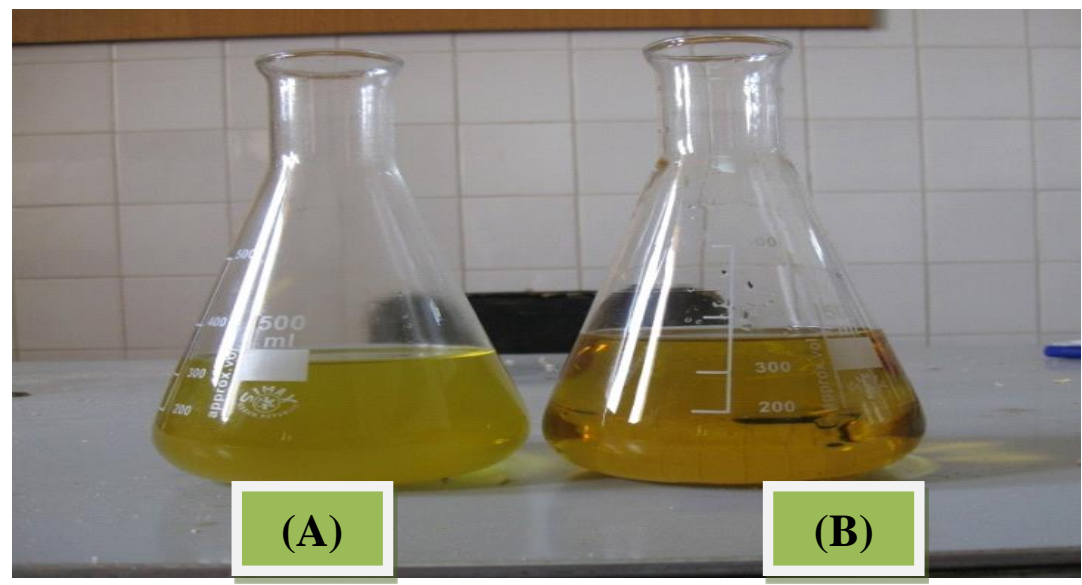

Fig. 9. The biodiesel before (A) and after washing + drying (B)

\subsubsection{Dry washing}

Although the water washing is the most common method used in purifying biodiesel, this method has a lot of disadvantages. The use of water to wash biodiesel causes many problems like:

-Water washing produces a large amount of waste water that must be treated.

-Water washing introduces water to the fuel. So after washing, the fuel must be dried to remove the trace amounts of water. This causes an increased energy cost.

-If the biodiesel has a high soap level, then water washing can lead to emulsions that can cause significant yield loss and other operational problems.

-Water washing can increase the processing time because of the need for drying, multiple washes, and separation water from biodiesel.

So, dry washing of biodiesel can alternate the water washing process effectively. There are several methods used in purifying biodiesel as dry washing like using magnesium silicate (Magnesol) as an adsorbent material and ion exchange resins. Low cost materials were used such as grind bagasse, saw dust and grind rice husk. Also magnesium silicate used in the dry washing because of their adsorbent characteristics. Table (1) and Fig. (10) showed the four parameters that were measured comparing the materials that used in this process, Water content, glycerol and methanol and comparing them with using water washing in the purification.
Table 1. Comparison between water and dry washing

\begin{tabular}{|c|c|c|c|}
\hline Method & $\begin{array}{c}\text { Water } \\
\text { content, } \\
\%\end{array}$ & $\begin{array}{c}\text { Methanol, } \\
\%\end{array}$ & $\begin{array}{c}\text { Glycerol, } \\
\%\end{array}$ \\
\hline grind bagasse & 0.04 & 0.01 & 0.23 \\
\hline $\begin{array}{l}\text { grind rice } \\
\text { husk }\end{array}$ & 0.045 & 0.01 & 0.24 \\
\hline saw dust & 0.045 & 0.02 & 0.24 \\
\hline Magnesol & 0.05 & 0.02 & 0.23 \\
\hline $\begin{array}{c}\text { Water } \\
\text { washing }\end{array}$ & 0.2 & 0.03 & 0.24 \\
\hline Standard & $\begin{array}{c}0.05 \\
\text { (DIN EN } \\
14214)\end{array}$ & $\begin{array}{c}0.01-0.5 \\
(E N \\
14110)\end{array}$ & $\begin{array}{c}0.25 \\
(D 6584)\end{array}$ \\
\hline
\end{tabular}

From the previous table, in the water content test it showed that in dry washing the water content was in the allowable level, but in the water washing it was above the allowable level so it needs to dry to get of any content of water in biodiesel which could cause corrosion on it.

The dry and water washing in glycerol and methanol content showed close results and all of them were in the allowable level. 

for diesel fuel in rural communities

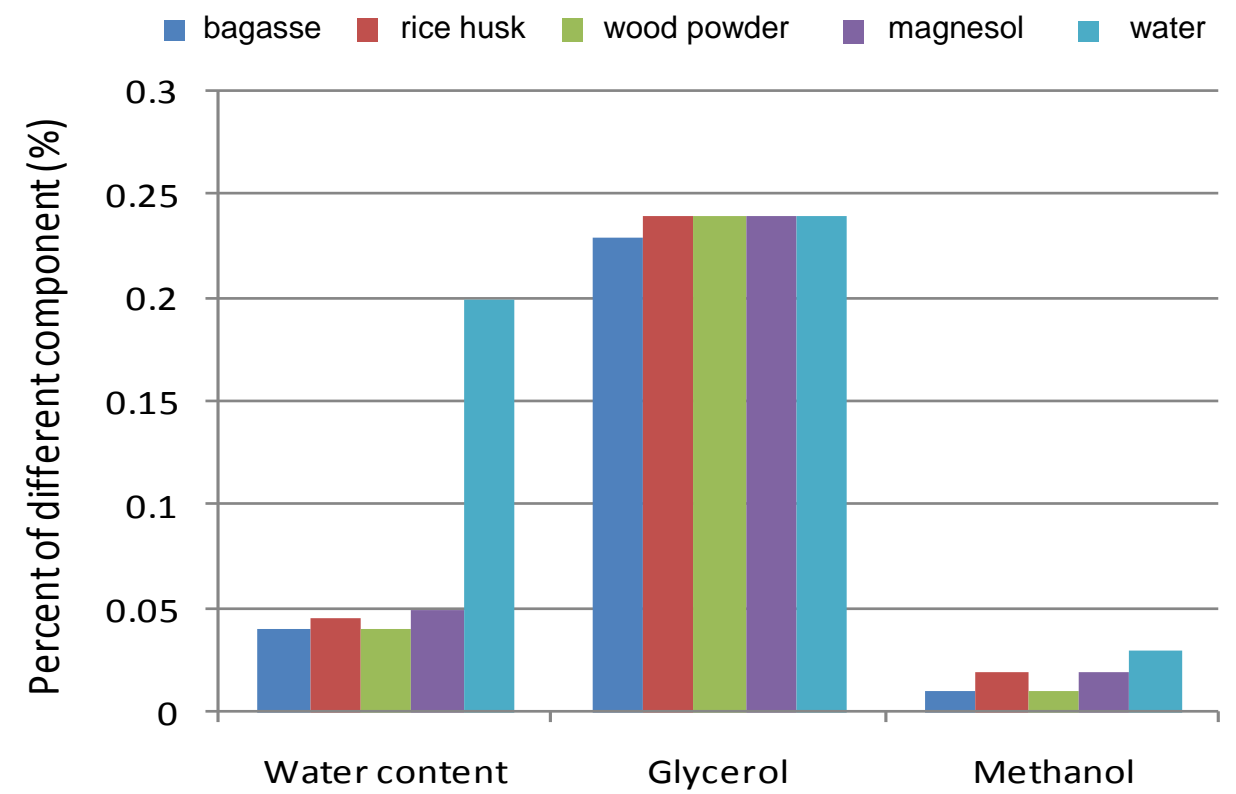

Fig. 10. Comparison between water and dry washing effects

\section{SUMMARY AND CONCLUSION}

- Increasing the times of biodiesel washing, clearing the washing water color from milky to very clear.

- Biodiesel transparency is better after washing than before washing.

- Water, methanol and glycerol contents were $0.04,0.01$ and $0.23 \%$ respectively with using grind bagasse, but they were $0.2,0.03$ and $0.24 \%$ respectively with using water in purification process. So the bagasse grind was better than other materials in purification process of canola biodiesel.

\section{REFERENCES}

Arun, K.V., Chattopadhyay, S.K. and Sen, S.R. 2013. Fuel properties, engine performance and environmental benefits of biodiesel produced by a green process. Applied Energy, 105, 319-326.

Berman, G.Y., Conceicao, E.D. and Gerpen, W.R. 2011. Biodiesel processing and production. Fuel Processing Technology, 86, 10971107.

Caylr, L.P. and Kusefoglu, U.T. 2008. Environmentally friendly production technology of biodiesel. Jelgava, 28, 161-164.

Conceição, M.M., Candeia, R.A., Silva, F.C., Bezerra, A.F., Fernandes, V.J. and Souza,
A.G. 2007. Thermoanalytical characterization of castor oil biodiesel. Renewable and Sustainable Energy Reviews, 11(5), 964-975.

Elshazly, S.S. 2015. Manufacturing a new dry wash unit for biodiesel purification and comparing it with wet wash method. Alexandria University, Egypt. 80 p.

Joshi, H.C. 2008. Optimization and characterization of biodiesel production from cottonseed and canola oil. Doctoral Dissertation, Clemson Univ., 277 p.

Moussa, A.I. 2003. Transesterification process to manufacture methyl ester of waste vegetable oil. The $11^{\text {th }}$ Annual Conference of the Misr Society of Agric. Eng, Egypt. pp. 851-866.

O'Brien, R.D. 2004. Assessment of a dry and a wet route for the production of biofuels from microalgae: energy balance analysis. Bioresource Technology, 102(8), 5113-5122.

Saengprachum, S.J., Ogunsina, B.S., Adelaja, A.O. and Ogbonnaya, M. 2013. Study of an Effective Technique for the Production of Biodiesel from Jatropha Oil. J. of Emerging Trends in Engineering and Applied Sci., 2(1), 79-86.

Schuchardt, C.M., Rios, S.D., Torras, C.G., Salvado, J.F., Mateo-Sanz, J.M. and Jiménez, L. 1998. Microalgae-based biodiesel: A multicriteria analysis of the production process using realistic scenarios. Bioresource Technology, 147, 7-16. 